\title{
AS REDES SOCIAIS E A VIRTUALIZAÇÃO DO CONSUMO: DESAFIANDO A PUBLICIDADE E O DIREITO
}

\section{SOCIAL NETWORKS AND CONSUMPTION VIRTUALIZATION: DEFYING ADVERTISING AND LAW}

\author{
1Jean Eduardo Aguiar Caristina
}

\section{RESUMO}

Este presente artigo, cuja metodologia foi o levantamento bibliográfico, tem por intuito provocar uma reflexão sobre a virtualização do consumo como consequência do hiperindividualismo implementado pelas redes sociais, com potencial para superar até mesmo os espaços físicos destinados à competição e ao prazer hedonista: os shoppings centers. Esta transformação do locus de consumo implica em mudanças estratégicas do mercado, especialmente no tocante à publicidade, tornando real o desafio do direito como instrumento de regulação de novas tecnologias e preservação da intimidade desse novo consumidor.

Palavras-Chave: Consumismo; Redes Sociais; Consumo Virtual; Publicidade; Segurança do Consumidor

\begin{abstract}
This article, whose methodology was the bibliographical survey, aims to provoke a reflection about the consumption's virtualization as a consequence of hyperindividualism implemented by social networks, with potential to overcome even the physical spaces destined for competition and hedonistic pleasure: the shopping centers. This transformation of the "locus" of consumption implies in strategic changes of market, especially in relation to advertising, making real the challenge of the law as a regulations instrument of new technologies and preservation of the intimacy of this new consumer.
\end{abstract}

Keywords: Consumerism; Social Networking; Virtual Consumption; Advertising; Consumer Safety

\footnotetext{
${ }^{1}$ Doutor em Direito Econômico pela Pontifícia Universidade Católica - PUC, São Paulo (Brasil).

Coordenador e Professor do Curso de Direito pela Universidade Nove de Julho - UNINOVE, São Paulo (Brasil).

E-mail: jean.caristina@gmail.com
} 


\section{INTRODUÇÃO}

O grande enigma da atual sociedade de consumo não é saber o que, mas até quando iremos consumir. A economia, que sempre se preocupou com os bens escassos, parece ter se rendido à (triste) realidade de que não é mais a escassez o centro nevrálgico dos grandes movimentos econômicos, deixando de navegar a onda da viabilidade material para ficar à mercê dos interesses - nem sempre claros - dos consumidores.

Crises, fases, movimentos e tantas outras influências externas e imprevisíveis são, agora, temores de mercado, em maior escala do que o simples risco da escassez. A massa e seu (possível) desinteresse se tornaram mais ameaçadores do que a notícia de que a produção de um determinado derivativo está em risco.

Essa substituição ocorreu pela sedimentação da chamada sociedade de consumo, consistente numa massa de alienados que experimentam apenas prazeres artificiais e não medem esforços para adquirir bens necessários à satisfação momentânea do consumo. Uma visão absolutamente individualista toma conta dos consumidores, que já não guardam nenhuma preocupação com o mundo exterior, mas apenas com o preenchimento dos espaços vazios de suas vidas.

O problema que cerca essa sociedade é ainda mais grave: hedonista e sem ideologias claras, ela está cada vez mais dispersa, fruto da virtualidade das relações, consequência do aumento da distância (de tudo) estabelecida pelas redes sociais e pela violência (de todo gênero) ao redor do mundo.

A sociedade de consumo no pós-modernismo, altamente individualista e de prazeres fugazes, se distancia cada vez mais do mundo real. A massa agora vive num mundo virtual, relacionando-se, comunicando-se e consumindo.

Os shoppings centers, templos do consumismo, com o passar do tempo perdem a capacidade de ser referência para o consumismo midiático, pois o consumista já não precisa do espaço físico; não é limitado pela insuficiência de recursos financeiros - o cartão de crédito e os meios eletrônicos de pagamento tiveram papel fundamental nesse aspecto -; tampouco tem preocupação com a escassez dos bens naturais, que no mundo virtual parece ser apenas uma história.

O novo consumidor, alienado do meio, vive um "universo virtual" de bens e 
recursos, substituindo a árdua tarefa de ir aos shoppings, do planejamento financeiro, da obrigação de decidir e de conviver com outros consumistas, além de não precisar se confrontar com realidades que, no imagético das redes, passam longe, despercebidas ou são simplesmente omitidas.

O consumidor vem se transformando e, com ele, os mercados se adaptam para cada vez mais virtualizar o consumo, evitando-se que os consumidores sejam obrigados a conviver em ambientes em que as sensações de medo, angústia, nervosismo e tantas outras inerentes ao consumo possam refreá-lo de seu intento.

Esse artigo pretende demonstrar como essa sociedade de consumo em transformação tem se afastado dos meios reais, transportando suas angústias para o campo virtual das relações, envolvida por publicidade que, sob o argumento de informar e divulgar, impõe ideologias que alimentam o hedonismo, o utilitarismo e o individualismo material, e como o direito deve ser reorganizar para enfrentar questões novas relativas à conectividade, à segurança da informação e à proteção aos direitos do novo consumidor.

\section{O NÃO-LUGAR DO CONSUMO}

Consumir é inerente à espécie humana e desperta sensações como dúvida, medo, alegria, temor, ansiedade e outras, a depender de quem, quando, onde e o que se consume. A experiência de consumir faz parte da evolução e representa a capacidade humana de organizar esforços para a obtenção de bens que lhes garanta bem-estar.

Com o passar do tempo, vitimado pela massificação da comunicação e da produção em larga escala, o consumidor perdeu o direito à dúvida. As experiências e todas as sensações existentes no ato de consumir já não podem mais ser sentidas, pois somente os fracos é que se questionam, refletem sobre formas e meios, põem em dúvida sua capacidade de comprar, a necessidade de ter e tantas outras indagações.

Os bens de consumo tornaram-se identidade social que garantem a permanência do consumidor em determinadas camadas do organismo social. A produção para benefício da vida humana foi derrotada para a vida humana em benefício da produção. Os bens deixaram de ser produzidos para benefício dos indivíduos e agora servem para a estabilidade dos mercados. Esse consumo utilitarista eliminou a possibilidade da dúvida e destruiu os freios éticos que outrora serviram para impedir aventuras consumistas. Os sentidos não fazem mais sentido no 
mercado de consumo e as dúvidas são fragilidades próprias dos perdedores. Há que ser destemido na sociedade de consumo por ser o único modo de inclusão e de aproximação aos estereótipos de felicidade e prosperidade.

Os shoppings centers, compassados com essas transformações da sociedade de consumo, criaram espaços ilusoriamente pacíficos de convívio, garantindo proteção contra a violência das ruas e conforto para o consumidor ao reunir, num só teto, diversas marcas e produtos para oferecer aos interessados experiências muito prazerosas do que o árduo trabalho de peregrinar entre ruas, lojas e bairros.

O crescimento das cidades alavancou o aumento do número de shoppings ao redor do mundo. Com o incremento urbano vieram também o trânsito, a violência, a segregação social, o desemprego e tantos outros problemas inerentes ao desenvolvimento desorganizado dos centros urbanos vitimados pelo turbocapitalismo (LUTTWAK, 2001). Esse capitalismo dinâmico e veloz, ao mesmo tempo desorganizado e altamente destrutivo (SCHUMPETER, 1961, p. 110), impôs às cidades e aos seus membros profundas transformações, realçando o individualismo, a competição e o abandono afetivo dos espaços públicos e das pessoas.

Ao mesmo tempo que a cidade real - ou o "mundo de fora" - desencadeia uma série de problemas para muitos, possibilita "alternativa" para poucos, como a criação do shopping center, a nova cidade do capital, a catedral onde uma parcela da população idolatra as mercadorias e vivencia prazeres reificados. Mas, se a "catedral das mercadorias" faz sucesso hoje colocando o shopping center como um dos empreendimentos mais rentáveis e com maior taxa de crescimento em todo o mundo capitalista, parece ser necessário reconhecer que sua origem e seu desenvolvimento estão interagindo historicamente com o desenvolvimento do espaço urbano na complexa lógica do capital. (PADILHA, 2004, p. 128-129)

Os shoppings, em meio ao caos das cidades, se tornaram oásis de prazer e luxo, protegendo os cidadãos de sua própria cidadania a ponto de convencionar-se, veladamente, que nesses espaços privados não se deve reproduzir as mazelas e vícios dos espaços públicos. Exemplo desta repugna social foram os "rolezinhos" entre 2013 e 2014, movimento de jovens de classes menos favorecidas que utilizaram os shoppings de diversas regiões do país para fazer seus encontros. Embora tenha havido excesso de publicidade em torno do fenômeno, de certo modo a população foi arrancada de sua zona de conforto para discutir o problema da segregação social nas grandes cidades. Ficou claro, nos meses em que diversos rolezinhos foram marcados em shoppings de todos os grandes centros que "o descontentamento vinha das camadas médias e altas, que sentiam a sua paz ameaçada em lugar até então protegido da desigualdade" 
(PINHEIRO-MACHADO e SCALCO, 2014).

O discurso silencioso dos shoppings é de que ali estão protegidos não apenas da violência das ruas (no seu sentido mais amplo), mas também do julgamento da sociedade. No interior dos shoppings os consumidores podem ser consumistas, materializar seus vícios sem que sequer uma crítica possa ser-lhes feita. Não há pecado nos shoppings. As sacolas representam a pilhagem dos vencedores.

Estilo monumental dos magazines, decorações luxuosas, domos resplandecentes, vitrines de cor e de luz, tudo é montado para ofuscar a vista, metamorfosear o magazine em festa permanente, maravilhar o freguês, criar um clima compulsivo e sensual propício à compra. $\mathrm{O}$ grande magazine não vende apenas mercadoras, consagra-se a estimular a necessidade de consumir, a excitar o gosto pelas novidades e pela moda por meio de estratégias de sedução que prefiguram as técnicas modernas do marketing. Impressionar a imaginação, despertar o desejo, apresentar a compra como um prazer, os grandes magazines foram, com a publicidade, os principais instrumentos de elevação do consumo a arte de viver e emblema da felicidade moderna (LIPOVETSKY, 2007, p. 31).

Os shoppings mantêm certo padrão de comportamento, pois padronizam linguagens e possibilitam a criação de senhas de pertencimento e reconhecimento social entre seus membros (HENNIGEN, 2010, p. 1.177). Os que estão dentro são parte do processo e os que estão fora, sem nenhum constrangimento, são os perdedores, os excluídos.

Na violência dos shoppings a exclusão é tolerada com tranquilidade. Os vitoriosos, os consumidores, não se incomodam com a existência de um universo de excluídos do lado externo do muro. Essa tolerância é um juízo negativo acerca do tolerado, ou seja, repugnam-se uns aos outros sem interferências. Não se trata de uma coexistência, mas de uma existência isolada, cada um dentro de seu universo de tolerância. Os shoppings também são segmentados por classes e níveis sociais, havendo os destinados às classes $\mathrm{A}$, os reservados às classes $\mathrm{B}$ e $\mathrm{C}$, e assim por diante, o que denota que até mesmo entre os incluídos há exclusões quanto aos níveis de linguagem e de individualismo de seus membros.

Estar in significa deter o poder de compra; podendo consumir, o indivíduo tem acesso à produção com a marca do sistema; vítima de um "engodo", os ingênuos consumidores se supõem participantes, de alguma forma, dos mecanismos de produção e, a reboque deste, do próprio núcleo de poder. Todavia, seu papel nunca é o de ator, mas sim o de espectador - as "falas" são consumidas e absorvidas sem choque e todo produto vindo da indústria cultural já se encontra pronto, não aceitando qualquer tipo de retoque os mesmo de diálogo (MESQUITA, 2002, p. 50). 
A seu modo, os shoppings promovem uma ambientação cultural, social, política e econômica entre seus membros, pois exigem subjetivações em que o reconhecimento do outro é preponderante para convívio. Esses espaços realçam os traços individualistas dos membros da sociedade de consumo, tornando o convívio suportável apenas sob a condição de se aceitarem a competição e o hedonismo.

Portanto, os shoppings protegeram os indivíduos da selvageria do mundo exterior e os lançaram noutra: na do consumismo, realçando traços típicos de uma sociedade egoísta, individualista, de prazeres imediatos e cujas necessidades são indetermináveis ou determináveis por poucos instantes, até que outra sobrevenha.

Porém, esses espaços sagrados correm o risco de serem profanados pela concorrência do hiperindividualismo da sociedade virtual de consumo. As redes sociais, o comércio eletrônico e a incapacidade de se compreender e satisfazer as novas - e dinâmicas necessidades humanas tornam os shoppings espaços de não identificação, pois em tempos de individualismo exacerbado não é tarefa simples saber como pensam e o que desejam seus membros, seja porque inexiste uma personalidade firme quanto ao consumo, seja porque, quando há, ela está sujeita a sofrer alteração ao sabor de um novo lançamento, uma movimentação do grupo em que está inserido, uma liquidação etc.

A desorganização das estruturas frente ao hiperindividualismo é apontada por Gilles Lipovetsky (2004, p. 56):

O hiperindividualismo coincide não apenas com a internalização do modelo do homo oeconomicus que persegue a maximização de seus ganhos na maioria das esferas da vida (escola, sexualidade, procriação, religião, política, sindicalismo), mas também com a desestruturação de antigas formas de regulação social dos comportamentos, junto a uma maré montante de patologias, distúrbios e excessos comportamentais. Por meio de suas operações de normatização técnica e desligação social, a era hipermoderna produz num só movimento a ordem e a desordem, a independência e a dependência subjetiva, a moderação e a imoderação.

As transformações que a virtualização do convívio social está ocasionando são imensuráveis. A escola, o trabalho, as relações amorosas, a arte, a política, enfim, não há uma só área que esteja protegida das mudanças. As relações de consumo não ficariam de fora, especialmente porque o consumo é um dos mais importantes propulsores do desenvolvimento. A fundamental transformação é que ao se virtualizar o convívio, a hiperindividualidade pode ser exercida sem sujeição à competitividade, nem há necessidade de se formarem juízos de 
tolerância a respeito dos excluídos.

O individualismo exercido antes em coletividades (a exemplo dos shoppings), isto é, em ilhas sociais que vez ou outra se agrupavam sob o teto dos shoppings para fins de demonstração e competição por meio do consumo, agora é exercido na singularidade do consumidor, que já não compra para se parecer com o outro, até porque, nesta hiperindividualidade virtualizada, o outro é apenas uma ideia, um reflexo do que o meio publicitário lhes induziu a pensar existir.

\section{CONSUMISMO E INDIVIDUALISMO}

O consumismo nada mais é do que o consumo exercido em nível de vício e é o resultado de um desnorteamento da sociedade inserida nos meios de consumo, que só encontra razão de ser na possibilidade imediata de possuir bens. A vida humana tem se tornado um exercício de sobrevivência e constante batalha pela manutenção do que se costuma chamar de “padrão de vida". Nunca a ideia do "cada um por si” foi tão real (FERRAZ JUNIOR, 2009, p. 23).

Porém, assim como o artista depende do palco, o consumista precisa de espaço próprio não apenas para consumir, mas para que possa expor sua individualidade, sem a qual inexistem parâmetros para a competição e disputa social. Não há individualidade que não tenha que ser exposta no meio, sem o qual não há porque se desenvolverem as individualidades (ELIAS, 1999, p. 33). É bem verdade que o homem, em sua individualidade, possui características do todo. Há uma via de mão dupla: os indivíduos adquirem características próprias da sociedade, que, a seu turno, incorpora as singularidades para formar uma união de partes fracionadas (NOGUEIRA, 2011, P. 65).

A dependência da sociedade pelos indivíduos é, na verdade, uma luta por espaço, no qual só se estabelecessem aqueles capazes de se tornar importantes para o próprio espaço, não por sua importância política, cultural ou intelectual, que parecem já não ter grande relevância quando contrapostas à selvageria, mas uma importância enquanto elemento referencial para o grupo, isto é, os membros da sociedade devem ser ao mesmo tempo idolatrados e odiados, mas facilmente esquecidos ou substituídos por outros que detenham maior capacidade de exposição. Os referenciais da sociedade são tão artificiais quanto as identidades que defendem, mas há um pacto silencioso da sociedade que aceita esses membros 
sem grandes questionamentos.

Jean Baudrillard (1991, p. 57) considera que "não há direito ao espaço senão a partir do momento em que já não existe espaço para todos e em que o espaço e o silêncio constituem o privilégio de uns quantos, à custa dos outros". Essa sociedade fragmentada, formada pelo conjunto de individualidades hedonistas e egoístas, forma indivíduos sem personalidade. O conjunto não passa de um amontoado, um agrupamento de pessoas artificialmente construídas a partir de referenciais não menos artificiais, que propagam uma vida perfeita e feliz.

Em meio a essa sociedade de referenciais efêmeros o discurso do consumo como forma de se encontrar a felicidade se tornou um norte para os mais frágeis. Mas não se trata de uma felicidade que encontra no outro a razão de ser, como se poderia pensar, mas tão somente nos bens que o outro demonstra ter (mesmo que não os tenha). Na psique do consumo a alegria não está em compartilhar do mesmo bem-estar do seu referencial, mas em compartilhar os mesmos bens, que são, segundo o meio publicitário, a única via do prazer. Não à toa a publicidade sempre se utiliza de verbos conjugados no imperativo para ordenar ao destinatário o consumo de determinado produto.

Max Horkheimer e Theodor Adorno (1973, p. 55) apontam características desse universo de consumidores sem ideologia e sintetizam que os indivíduos, por causa da revolução industrial, passaram a lutar apenas por seus próprios interesses, desprezando o espírito de coletividade. Eles não enxergam mais o outro e não se determinam por sua posição dentro do grupo; há uma determinação social que se impõe pela força do consumo, um autoposicionamento a partir da força selvagem do ter (BAUMAN, 2008, p. 184) e não pela capacidade de se parecer.

A aceitação de ideologias de massa normalmente propagadas por referenciais midiáticos e artificiais exclui a repercussão dos próprios sentimentos e formas de pensar (HORKHEIMER e ADORNO, 1973, p. 78-87). Os indivíduos vivem ideologias emprestadas, conscientes de que não são resultado de sua razão pessoal, mas condição para seu pertencimento. Mesmo correndo o risco de uma possível ilegitimidade, numa espécie de relação cínica entre o indivíduo e o meio (HORKHEIMER e ADORNO, 1973, p. 191), preferem viver como avatares de ideologias emprestadas, dada a facilidade de aceitação, pelo grupo, de ideologias já existentes e testadas pela sociedade.

O homem como produto de si mesmo, reprodutor de modelos impostos por referenciais midiáticos, se condena a uma excessiva individualidade (LIPOVETSKY e 
SERROY, 2011, ps. 31-32) e à perda dos freios que antes julgavam seus atos e lhes forçava a refletir e a resistir. A consciência e a culpa são apenas obstáculos, e não mais balisamentos.

A indústria cultural denunciava os comportamentos de massa. Parecia sugerir que a racionalidade estaria na emancipação individual. Ou, na perspectiva marxista, na libertação coletiva. Nada disso ocorreu até agora. Na sociedade midíocre, caracterizada pela customização e pela segmentação, massa é um estado de espírito, um comportamento individual ou grupal que mimetiza a felicidade do rebanho, uma atitude de falsa iniciativa que se acomoda passivamente ao simulacro da ação. Cada consumidor quer exatamente o que deve querer. Não há mais manipulação nem imposição. A mídia dá ao seu cliente o que ele quer. Justamente aquilo que a mídia gostaria de dar-lhe. Essa coincidência absoluta gera paz nos espíritos. É o sistema da moda: ser diferente é estar de acordo com outros conforme uma maneira de existir ou de viver transitória, embora eterna na sua intensa efemeridade, comprada pronta. (SILVA, 2012, p. 14)

Essa vida para o consumo é uma apatia ideológica, de referenciais destrutivos, impostores de uma marca totalitária que propõe um único modo de vida, tornando os consumidores em massa sem capacidade de manifestar racionalmente suas vontades pessoais; são apenas copiadores, seguidores de tendências, repetidores de ideias que não lhe pertencem.

Os shoppings reúnem as individualidades como se os seus membros estivessem num ringue, disputando uma luta em que o vencedor não supera o adversário, mas a si mesmo, e se torna, pela selvageria de sua capacidade econômica, também ele um referencial (FERRAZ JUNIOR, 2009, p. 84), invejado, sentimento este que “[...] tornou-se categoria positiva, glorificada socialmente" (CANIATO e RODRIGUES, 2012, p. 32).

Porém, vem perdendo a sua força na medida em que o parecer com o outro nesse processo de busca de identificações já não depende do espaço físico. O shopping agora está na ponta dos dedos, nas redes sociais. A sociedade que se desejou bonita, perfeita, acolhedora e pacífica foi transportada para o interior dos shoppings centers. Agora, por causa da influência das redes, essa sociedade é transportada para o mundo virtual. Os referenciais, antes físicos, vivem apenas na publicidade que entra diuturnamente na vida das pessoas por meio das redes. A digital dos consumidores se chamam cookies, que mostram para o mundo suas preferências, seus desejos, suas inclinações, como se identidade e privacidade fossem palavras apenas simbólicas. 


\section{OS “AMIGOS” DESCONHECIDOS}

O consumo desenfreado e hedonista não foi o único responsável pelo individualismo que vem transformando a sociedade moderna. As redes "sociais" afastaram os indivíduos justamente dela: a vida social. Sob a curiosa nomenclatura de "sociais" faz crer, semanticamente, que são o novo espaço de convívio das sociedades.

O esfacelamento das amizades e das conexões pessoais deu lugar a redes virtuais de amizade, curtidas no espaço vazio, sorrisos não sorridos. O real deu lugar a dados tecnológicos que substituem o carisma, a ternura, o toque, o olhar. Nem mesmo a voz importa, mas preferem-se as longas, porém seguras - pois dispensam possíveis interações indesejadas , digitações, apenas pelo prazer de continuar vivendo o ambiente do virtual.

Os famosos também já não produzem cultura. Eles são fruto da cultura de se desejar seus modos de vida, a exemplo dos "youtubers" e dos queridinhos das redes sociais que possuem milhões de seguidores. Ninguém ao certo sabe como são suas vidas, pois para a massa não importa, o show apenas deve continuar. Assim como no filme "A vida de Truman", a sociedade se tornou um grande telespectador do outro. E assim como no filme, o fim de uma transmissão já não é mais importante, ou seja, a vida e a morte são fenômenos já não tão distintos entre si.

As amizades, as relações familiares e os relacionamentos amorosos são conquistas não menos hedonistas. Curtem-se páginas, criam-se amizades, formam-se grupos que não têm identidade alguma senão pela mera troca de dados eletrônicos. $\mathrm{O}$ individualismo promovido pelas redes sociais, diferentemente daquele que é preciso ser mostrado nos centros "sociais" de consumo, com alta dose de competição e de demonstração, distancia os consumidores que não precisam mais da exposição pessoal. Agora, basta seguir os modelos fictícios de vida que o meio publicitário impõe, ou seja, as aparências de plenitude dos novos referenciais.

Esse novo individualismo não precisa mais do meio, tornando dispensáveis os ringues em que se confrontavam as individualidades. Essa individualidade tecnológica dispensa a obrigação de se frequentar o shopping. A segurança está no quarto, na casa. O novo "meio social" não existe fisicamente, mas apenas enquanto durar a bateria do celular ou o crédito de internet. 
O MMA Mobile Report Brasil 2016², organizado pela MMA Latam, entrevistou 1.200 homens e mulheres para aferir suas preferências no que tange ao uso de smartphone e principais interesses. Os aplicativos mais acessados são: Whatsapp, Facebook, Instagram e Youtube. Dos entrevistados, 39\% admitiram ter visto publicidade por meio online. Dentre a geração Millenials (geração nascida após 1980), por exemplo, 68\% admitiram ter visto publicidade no Facebook em 2016, contra apenas 37\% em 2015. Os dados também mostram aumento do grau de atenção à publicidade. Um dado interessante é que a totalidade dos entrevistados considerou a casa o melhor lugar para ver propaganda.

No conforto de seu quarto o consumidor é tão ou mais interessante quanto o do shopping, com um diferencial: o mercado não o conhecerá fisicamente. Isso faz diferença quanto a estratégias de publicidade, pois as lojas são organizadas para atrair os indivíduos e deles extrair suas ambições hedonistas, tais como fotos com lindos modelos, manequins que representam o ideal de corpos perfeitos, cores, músicas e odores que mexem com os sentidos e outras tantas estratégias de conquista de consumidores.

Encontramo-nos, portanto, no desafio de saber quais serão os próximos passos dessa sociedade altamente individualizada e, agora, além de não identificada ideologicamente, não identificável fisicamente. O mercado organizado se vê diante de uma rede de consumidores invisíveis, capazes de consumir tanto ou mais, mas cuja penetração se dará pela confirmação do individualismo, afinal, negá-lo seria impensável. Para sucesso desse intento o mercado deve tornar o consumidor ainda mais individualista, trabalhar com seus desejos mais íntimos e emoções, ou seja, extrair das redes suas preferências e ambições, moldando sua identidade na medida dos interesses de produção. Mais complexo e tormentoso do que encontrar uma identidade é mantê-la e protegê-la do meio, segundo Zygmunt Bauman, (2008, p. 187), e os mercados têm esse desafio: formar e aprisionar.

O problema está justamente no fato de que o consumismo conhecido - e já não tolerado -, de publicidade enfática, indutora, que sublinha o hedonismo e induz toda espécie de instinto individualista, pode, nesse novo cenário, tornar-se ainda mais violento, pois deverá, na sociedade em rede, buscar um consumidor não frequente aos shoppings e que espera ser alcançado, isto é, as marcas que deixa nas redes são pistas do que espera que lhe seja oferecido.

\footnotetext{
${ }^{2}$ http://www.mmaglobal.com/files/documents/mma_mobile_report_2016_brasil_largeversion.pdf. Acesso em 26 dez. 2016.
} 


\section{NÃO TE CONHEÇO, MAS SEJA BEM-VINDO}

O mercado tem pela frente dois grandes desafios: primeiro, identificar o novo consumidor, esse indivíduo que não compartilha suas experiências em espaços físicos; segundo, tomar a difícil decisão de afastá-lo ainda mais da sociedade. Negar seu viés individualista é um erro. Pretender coletivizá-lo, idem.

Daí ressurge a crítica, a partir de um reconhecimento óbvio, de que o consumidor já não forma a sociedade de consumo, mas o meio é que se organiza para criá-lo à sua imagem, ao que se denomina “economia de marketing” (BENJAMIN, 1994, p. 61). Isso é o que Zygmunt Bauman denomina de "vendabilidade" (2007, ps. 75-76):

A maioria das mercadorias oferecidas no mercado de consumo deve sua atração e seu poder de recrutar consumidores ávidos a seu valor de investimento, seja ele genuíno ou suposto, anunciado de forma explícita ou indireta. Sua promessa de aumentar a atratividade e, por consequência, o preço de mercado de seus compradores está escrita, em letras grandes ou pequenas, ou ao menos nas entrelinhas, nos folhetos de todos os produtos - inclusive aqueles que, de maneira ostensiva, são adquiridos principalmente, ou mesmo exclusivamente, pelo puro prazer do consumo.

No mesmo sentido é o escólio de Milton Santos (2001, p. 48-49), que considera que o mercado, antes, produz o consumidor, aliena-o, desencadeia toda espécie de narcisismo e depois formata os produtos, que não servem necessariamente à satisfação do consumidor, mas à função de servir à produção (PADILHA, 2004, p. 142) e ao desenvolvimento econômico, responsabilidade que também foi posta aos consumidores. Se o consumismo é uma "economia de engano", pois "ele aposta na irracionalidade dos consumidores, e não em suas estimativas sóbrias e bem informadas; estimula emoções consumistas e não cultiva a razão" (BAUMAN, 2007, p. 65), como serão os próximos passos do consumismo se o consumidor pode ir shopping com um toque na tela de seu celular?

Há uma desestruturação em vista, pois o desmonte físico dos shoppings impactará, com o decorrer do tempo, na vida de milhares de trabalhadores, nas estratégias de marketing de empresas e na restruturação de diversas políticas econômicas. Nessa relação em que o consumidor é que se vende para o produto, sem intermediários ou conjuntos sensoriais que o levem a decidir a não ser seus próprios desejos íntimos, deverá ser superada a barreira do consumidor presente.

Manuel Castells afirma que o comércio eletrônico, apesar de movimentar bilhões 
de dólares em todo o mundo, não fará desaparecer os shoppings centers que, pelo contrário, proliferam em toda parte do planeta. $\mathrm{O}$ autor aponta que já está havendo uma adaptação das lojas, instalando terminais de compra on-line e com entrega no domicílio do consumidor (2000, p. 485).

Se a doença da sociedade foi o consumismo desenfreado, representado, fisicamente, por lojas e shoppings centers que pulularam ao redor do mundo, unificando modas e globalizando marcas, tornando as linhas geográficas cada vez apagadas, tem-se agora um paciente que sequer é visto, que vive no convívio silencioso de uma rede absolutamente dessocializante, sob a ótica da sociedade material, mas numa sociedade que faz sentido apenas nela própria.

\section{O DESAFIO DO DIREITO}

Reconhecer que o mercado deverá modificar seu curso em direção a uma maior alienação do consumidor e realce de seu individualismo e egocentrismo não é uma concordância ou aceitação, mas um resignado reconhecimento da incapacidade de ser freado o turbocapitalismo midiático (LUTTWAK, 2001).

A regra do art. $6^{\circ}$, inc. IV, da Lei $n^{\circ} 8.078 / 90$, que garante se tratar de direito básico do consumidor a proteção contra a publicidade enganosa e abusiva, mais uma vez, e ainda mais enfaticamente, virá à tona, especialmente com a definição dada pelo art. $37, \S 2^{\circ}$, que reputa abusiva a publicidade que incita a violência, explore o medo ou superstição, se aproveite da deficiência de julgamento e experiência da criança, desrespeita valores ambientais, ou que seja capaz de induzir o consumidor a se comportar de forma prejudicial ou perigosa à sua saúde ou segurança.

Não há como se proteger o consumidor "a priori", pois por mais que se possa indagar acerca de uma possível indução a um comportamento prejudicial à sua segurança financeira - o que, sinceramente, cremos na possibilidade de se fazê-lo, dada a necessidade de uma interpretação mais abrangente do conceito de segurança -, a restrição hermenêutica do dispositivo é evidente.

A publicidade, que na sua gênese é "instrumento multifacetado, voltado a introduzir, perpetuar ou aperfeiçoar uma atividade de mercado ou produto", deve ter como limitação não se prestar "à divulgação de ideias ou ideologias, a não ser aquelas ideias de 
consumo" (FEDERIGHI, 2009, p. 227). Na prática, a publicidade cria linguagens muito tênues para imposição destas ideologias tais como cores, modelos corporais, comportamentos, sensações de liberdade e de masculinidade e outras.

Especialmente nos países emergentes em que a produção industrial é emprestada dos países desenvolvidos, a publicidade tem, a um só tempo, o papel fundamental e perigoso de colocar o consumidor em pé de igualdade com aqueles de sociedades culturalmente mais preparadas, havendo, segundo Gino Giacomini Filho, uma queima de etapas, já que ainda existe certo atraso cultural em relação às sociedades ambientadas e aptas para o mercado de publicitário (1991, p. 48).

A publicidade não pode se firmar apenas no campo do marketing de produtos. É, acima de tudo, linguagem, e como tal, com capacidade indutora a depender da forma como se organiza para atingimento do consumidor. Afinal, segundo Lucia Santaella e Winfried Nöth (2010, p. 30) “o mercado é um cenário de comunicação não verbal, um espaço comunicativo no qual o complexo produtor e os consumidores trocam não só mercadorias, mas também ideias e valores".

O direito à informação, que é uma das vertentes da publicidade nas relações de consumo, é direito fundamental, e como tal exige que a publicidade seja sempre objetiva, evitando-se subjetividades que se utilizem das fragilidades dos consumidores para impor ideologias, desejos, sonhos e experiências que não existem na esfera subjetiva do consumidor.

Muito embora a livre iniciativa e o direito de propriedade, como elementos do capitalismo, declaradamente pertencentes ao ordenamento constitucional (SAYEG, 2013, p. 34), permitam margem de liberdade à publicidade, o direito constitucional à informação e à proteção contra a publicidade enganosa deve preponderar, sob pena de negação dos direitos humanos como um todo, já que, ao se proteger os frágeis, protege-se a todos (YUNUS, 2008, P. 22). Afinal:

Hoje, o que mais caracteriza a publicidade é o fato de ela vender ideias, valores, estereótipos e preconceitos. Os produtos anunciados são carregados de significados e de possibilidades e as emoções são muito mais exploradas que a utilidade do produto propriamente dita. A publicidade faz um serviço de depuração, de limpeza das coisas, pois ela mantém apenas o lado positivo do que anuncia. Os anúncios publicitários divulgam apenas a dimensão do que é bom nos produtos, quando, na realidade, sabemos que as mercadorias e os serviços também trazem consigo problemas, defeitos, contradições. Assim, a publicidade elimina aquilo que há de vida, que é real, 
que é da natureza das coisas. A recusa dessa dimensão nos objetos e atividades anunciadas torna o mundo falsamente harmonioso, fazendo da publicidade algo tendencioso, ilusório e falso (PADILHA, 2004, p. 145).

O discurso publicitário e todos os seus exageros racionalmente organizados para os fins pretendidos (BENJAMIN, 2005, p. 333) tem vertido para uma dominação do mais forte, que se impõe sobre fragilidades para lhes outorgar a tão desejada libertação. Segundo Jean Baudrillard (1991, p. 85):

Todo o discurso sobre o consumo procura transformar o consumidor no Homem Universal, na encarnação geral, ideal e definitiva da Espécie Humana, e considerar o consumo como as primícias da 'libertação humana', que acabaria por cumprir-se em vez de e apesar do fiasco da libertação política e social. Mas, o consumir nada tem de ser universal: surge como ser político e social, como força produtiva e como tal, suscita problemas históricos fundamentais, como os da propriedade dos meios de consumo (e já não dos meios de produção), da responsabilidade económica (responsabilidade quanto ao conteúdo da produção), etc. Também aqui se encontra a virtualidade de crises profundas e de novas contradições.

O novo consumidor, virtualizado e cada vez menos propenso a ocupar espaços físicos, deverá ser protegido pelo direito. Primeiro em relação aos exageros publicitários, devendo ser reinterpretado o conceito de segurança de que trata o art. $37, \S 2^{\circ}$, do Código de Defesa do Consumidor, para se incluir no rol de vedações as peças publicitárias causadoras de insegurança financeira ou psicológica no consumidor ou que possuam alta dose de indução psicológica à vida individualista e hedonista.

É grande o desafio por trás dessa tarefa, pois muitas peças publicitárias usam linguagem subjetiva que só têm potencial danoso na esfera individual do destinatário, ou seja, pode ou não ser abusiva a depender de quem, quando e como as receba e o grau de consciência e criticismo de seu destinatário, a exemplo das publicidades icônicas, cujo consumidor pode ou não compreender e depurar o processo publicitário, e se consciente de que se trata de um processo indutivo, mesmo assim lançar-se ao consumo, por entender que aquele produto, pelas qualidades que possui, pode materializar o ícone linguístico contido na publicidade. Seria este, portanto, um autoengano consciente, cuja identificação é tarefa muito mais árdua do que aferição de publicidades notadamente enganosas.

O segundo problema é a inclusão digital. Como, em sociedades tão heterogêneas e que ainda possuem largas desigualdades sociais, culturais, políticas e econômicas, podem ser negados os diferentes sistemas de comércio? Os shoppings e os sistemas virtuais de consumo 
ainda deverão existir para atender a todos os consumidores, inclusive deve haver proteção do consumidor quanto a diferenças de preço e de condições quando o mesmo produto é oferecido simultaneamente por dois meios de consumo, pois a discriminação de qualquer um dos meios significa exclusão. Manuel Castells (2000, p. 60) adverte para o problema da exclusão digital:

Parece haver uma lógica de excluir os agentes da exclusão, de redefinição dos critérios de valor e significado em um mundo em que há pouco espaço para os não-iniciados em computadores, para os grupos de consomem menos e para os territórios não atualizados com a comunicação. Quanto a Rede desliga o Ser, o Ser, individual ou coletivo, constrói seu significado sem a referência instrumental global: o processo de desconexão torna-se recíproco após a recusa, pelos excluídos, da lógica unilateral de dominação estrutural e exclusão social.

Um terceiro problema é em relação à segurança da informação, pois o consumidor virtualizado, que se utiliza da internet e das redes para consumir, deve ter seus dados e intimidade preservadas, pois a violação a esse direito constitucional, além de tipificar crime, torna o consumidor vulnerável a ações publicitárias.

É necessária uma profunda discussão em torno do que se entende por dados e intimidade, pois o debate pode se circunscrever apenas no que tange a dados pessoais e sigilos de correspondência, bancário e outros mais tradicionais. É possível entender que a proteção do consumidor também deve existir no que toca às suas preferências de navegação, suas buscas na rede e seus vínculos profissionais ou pessoais. É certo que, nas redes, o consumidor deixa digitais, isto é, impressões sobre sua personalidade e preferências. Assim, o mercado sabe quanto, quando e o que procuram os consumidores, apenas fazendo a leitura dessas impressões digitais, e oferecem, como que por mágica, aqueles produtos e aquelas peças publicitárias que possam satisfazer a procura do consumidor. Poder-se-ia dizer, ainda, que essa é uma forma atenciosa do mercado de ir ao encontro do consumidor. Todavia, em que momento o consumidor anuiu com a possibilidade de suas buscas e navegações poderem ser lidas pelo mercado para fins de compreensão de suas inclinações e desejos. E, por que não, seus vícios, seus problemas, suas decepções, afinal, se não há limites para que o mercado conheça seus bons desejos, também não há para que conheça seus vícios. E o resultado, para ambos, será o mesmo: tornarão base de dados para o lançamento de publicidade.

Por fim, há o problema da informação mais ampla acerca das utilidades e consequências pessoais e ambientais dos produtos, ou seja, a necessidade de prestação de informação ambientalmente responsável, capaz de mostrar ao consumidor que, virtual ou 
presencialmente, seu ato gera consequências no mundo real, tanto no que se refere à sua saúde e bem-estar, quanto para o meio ambiente, de modo que se registre na consciência do consumidor o seu dever social.

\section{CONCLUSÃO}

A sociedade de consumo, principalmente por conta do aumento da violência e das neuroses urbanas, encontrou nos shoppings centers o lugar ideal para convívio, estabelecendo como inerente ao espaço a aceitação da desigualdade social que afasta pobres e excluídos, e a competição como critério de permanência.

Os shoppings, mais do que aglomerados empresariais, adquiriram traços inegáveis da sociedade capitalista do último século, tornando-se um espaço de competitividade e individualismo, utilizado pelos consumidores para pelejar entre si ou para, a partir de seu poder econômico, demonstrar aos demais a sua força e poder, tornando-se referenciais aos outros.

Entretanto, as redes sociais e o poder de sedução de seus membros vêm retirando os indivíduos dos lugares reais de convívio, tornando-os hiperindividualistas, a ponto de os shoppings centers já não representarem mais o lugar de disputa dos consumistas. As redes virtualizaram os referenciais, ou seja, já não interessa parecer com o outro (físico, real), é preciso, agora, ser o próprio referencial em rede, sem as críticas e julgamentos que no meio real poderiam sofrer, e na velocidade que somente as redes sociais são capazes de garantir.

Os indivíduos, desnorteados pela ausência de ideologias claras, buscam prazer imediato nos bens e na possibilidade de gozarem da felicidade e bem-estar que a publicidade lhes induz a acreditar que existe, sem questionamentos sobre a verdade e sinceridade do que lhe é imposto.

O poder irrefreável das redes sociais já foi compreendido pelo mercado, que agora direciona seus esforços para esse novo consumidor, altamente individualista e que mergulha nas redes sociais tanto para convívio quanto para aquisição de bens. Noutras palavras, o avanço tecnológico, o aumento da violência das cidades, a complexidade da vida urbana e tudo o mais que cerca a atual sociedade tende a chancelar a exclusão do consumidor do mundo real (espaços físicos que integram a sociedade).

Disso resultará que a publicidade direcionada aos novos consumidores terá ainda mais traços individualistas, pois para manutenção dos consumidores em estado de êxtase é preciso que ele não enxergue o outro, mas seja reflexo do que o meio publicitário quer que ele seja, 
numa constante procura de realização material a partir de referenciais imagéticos.

Essa publicidade tem potencial para a formação de ideologias deturpadas, pois no afã de atingir o consumidor, nem mesmo sua intimidade é preservada. Nas redes, o consumidor acaba deixando digitais impregnadas pelo caminho, mostrando quais são suas preferências, seus vícios, seus desejos e todas as suas características, e isso será, para o mercado publicitário, instrumentos bastantes para o desenvolvimento de ações cada vez mais invasivas e capazes de atingir camadas mais profundas da consciência e subconsciência do consumidor, pondo em risco sua segurança emocional, patrimonial e comportamental, o que, a nosso ver, se torna obrigatório objeto de estudo pelo Direito.

\section{REFERÊNCIA BIBLIOGRÁFICA}

BAUDRILLARD, Jean. A sociedade de consumo. Tradução: Artur Morão. Lisboa: Edições 70, 1991.

BAUMAN, Zygmunt. A sociedade individualizada: Vidas contadas e histórias vividas. Tradução: José Gradel. Rio de Janeiro: Zahar, 2008.

BAUMAN, Zygmunt. Vida para Consumo: a transformação das pessoas em mercadoria. Tradução: Carlos Alberto Medeiros. Rio de Janeiro: Zahar, 2007.

BENJAMIN, Antônio Herman de Vasconcellos e. Das Práticas Comerciais. in GRINOVER, Ada Pellegrini [et al.]. Código brasileiro de Defesa do Consumidor: comentado pelos autores do anteprojeto. $8^{\mathrm{a}}$ edição. Rio de Janeiro: Forense Universitária, 2005. 57/105, 1994

Revista de Direito do Consumidor. São Paulo: Revista dos Tribunais, RDC 9/25, p.

CANIATO, Angela Maria Pires e RODRIGUES, Samara Megume. A construção psicossocial da competição: o engano na cumplicidade de uma falsa vida. in Revista Psicologia \& Sociedade. Número 24 (1). São Paulo, 2012, p. 23-35.

CASTELLS, Manuel. A sociedade em rede. Volume I. $8^{\text {a }}$ edição. Tradução: Roneide Venancio Majer. São Paulo: Paz e Terra, 2000.

COLOMBO, Caio. Hiperconsumo: comunicação, condicionamento e compras das décadas de decisão à década de descontrole. São Paulo: RG Editores, 2012.

ELIAS, Norbert. A sociedade dos indivíduos. Organização: Michael Schöter; tradução: Vera Ribeiro; revisão técnica e notas: Renato Janine Ribeiro. Rio de Janeiro: Zahar, 1994. 
FEDERIGHI, Suzana Maria Catta Preta. Algumas notas sobre a publicidade no CDC. In: SODRÉ, Marcelo Gomes; MEIRA, Fabíola; CALDEIRA, Patrícia (org.). Comentários ao Código de Defesa do Consumidor. São Paulo: Verbatim, 2009.

FERRAZ JUNIOR, Tércio Sampaio. Poder Econômico e Gestão Orgânica. In SALOMÃO FILHO, Calixto; NUSDEO, Fábio (org.). Poder Econômico: direito, pobreza, violência, corrupção. Barueri: Manole, 2009.

FREUD, Sigmund. Psicologia das Massas e Análise do Eu e outros textos (1920-1923). Tradução: Paulo César de Souza. São Paulo: Companhia das Letras, 2011.

GIACOMINI FILHO, Gino. Consumidor versus propaganda. São Paulo: Summus, 1991.

HENNIGEN, Inês. Superendividamento dos consumidores: uma abordagem a partir da Psicologia Social. Revista Mal-estar e Subjetividade, vol. X, n. 4, Fortaleza: Universidade de Fortaleza, dez. 2010.

HORKHEIMER, Max e ADORNO, Theodor W. Temas básicos de Sociologia. Tradução: Álvaro Cabral. São Paulo: Cultrix, 1973.

LIPOVETSKY, Gilles. A felicidade paradoxal: ensaio sobre a sociedade de hiperconsumo. Tradução: Maria Lucia Machado. São Paulo: Companhia das Letras, 2007.

LIPOVETSKY, Gilles. Os tempos hipermodernos. Tradução: Mário Vilela. São Paulo: Barcarolla, 2004.

LIPOVETSKY, Gilles e SERROY, Jean. A cultura-mundo: resposta a uma sociedade desorientada. São Paulo: Companhia das Letras, 2011.

LUTTWAK, Edward. Turbocapitalismo: perdedores e ganhadores na economia globalizada, Tradução: Maria Abramo Caldeira Brant e Gustavo Steinberg. São Paulo: Nova Alexandria, 2001.

MESQUITA, Dilma. Shopping Center: a cultura sob controle - as relações atuais entre literatura e sociedade de consumo. Rio de Janeiro: Ágora da Ilha, 2002.

PADILHA, Valquíria. Consumo e lazer reificado no universo onírico do shopping center. in GOMES, Christianne Luce. Dicionário crítico do lazer. Belo Horizonte: Autêntica, 2004)

PINHEIRO-MACHADO, Rosana e SCALCO, Lucia Mury. Rolezinhos: marcas, consumo e segregação no Brasil. in Revista de Estudos Culturais. Número 1. São Paulo: USP, 2014. Disponível em: http://www.each.usp.br/revistaec/. Acesso em 24 ago. 2016.

SANTAELLA, Lucia e NÖTH, Winfried. Estratégias semióticas da publicidade. São Paulo: Cengage Learning, 2010.

SANTOS, Milton. Por uma outra globalização: do pensamento único à consciência universal. $6^{\text {a }}$ edição. Rio de Janeiro: Record, 2001. 
SAYEG, Ricardo Hasson. Capitalismo Humanista diante da crise global, na visão de 2012. in CAMPELLO, Lívia Gaigher Bósio e SANTIAGO, Mariana Ribeiro (org.). Capitalismo Humanista e Direitos Humanos - estudos em homenagem aos Professores Ricardo Sayeg e Wagner Balera. Florianópolis: Conceito Editorial, 2013.

SCHUMPETER, Joseph. Capitalismo, Socialismo e Democracia. Tradução: Ruy Jungmann. Rio de Janeiro: Editora Fundo de Cultura, 1961.

SILVA, Juremir Machado da. A sociedade midiocre: passagem ao hiperespetacular (o fim do direito autoral, do livro e da escrita). Porto Alegre: Sulina, 2012. 